\title{
Safety and efficacy of abciximab as an adjunct to percutaneous coronary intervention
}

\author{
This article was published in the following Dove Press journal: \\ Vascular Health and Risk Management \\ I March 2010 \\ Number of times this article has been viewed
}

\author{
Jennifer Vergara-Jimenez \\ Pierluigi Tricoci \\ Department of Medicine-Cardiology, \\ Duke Clinical Research Institute, \\ Durham, North Carolina, USA
}

\begin{abstract}
Abciximab is a widely studied glycoprotein IIb/IIIa inhibitor, specifically in the setting of patients undergoing percutaneous coronary intervention (PCI). The populations studied have included patients with non-ST-segment acute coronary syndromes, ST-segment elevation myocardial infarction, and elective PCI. This large amount of information provides a clear efficacy and safety profile of the drug, although a few questions on the use of abciximab still exist, particularly on its use and preference in the setting of newer antiplatelet and antithrombotic medications. In this article we review the most relevant data from randomized clinical trials with abciximab in patients undergoing PCI and discuss the recent guideline recommendation on use during PCI.
\end{abstract}

Keywords: abciximab, percutaneous coronary intervention, glycoprotein inhibitor

Coronary artery disease affects about 16 million men and women in the United States, causing approximately 450,000 deaths every year. ${ }^{1,2}$

Percutaneous coronary intervention (PCI) is one of the current treatment options for coronary artery disease. The American Heart Association in their Heart Disease and Stroke statistics 2008 reports that 1,270,000 angioplasties were performed in the United States during 2005. ${ }^{3}$

Antiplatelet therapy is the mainstay of medical management during PCI. The principal objectives of antiplatelet therapy are to maintain the stent patency, reduce the risk of stent thrombosis, reduce the risk of periprocedural complications, and ultimately reduce the risk of important ischemic events such as death and myocardial infarction. Platelets are activated though a variety of agonists each acting on specific pathways. These all lead to a final common pathway which is the activation of the glycoprotein (GP) IIb/IIIa. Activated GP IIb/IIIa links to fibrinogen, and produces platelet aggregation (Figures 1 and 2).

GP IIb/IIIa inhibitors are a class of medication that act by blocking the GP IIb/IIIa receptor. This class has been extensively studied in patients with acute coronary syndromes (ACS) and those undergoing PCI. GP IIb/IIIa inhibitors currently available are intravenous agents: abciximab, eptifibatide, and tirofiban. Eptifibatide and tirofiban are small-molecule GP IIb/IIIa inhibitors, while abciximab is a humanized murine monoclonal antibody fragment (Figure 3).

Abciximab binds with high-affinity the GP IIb/IIIa receptor, resulting in slow off-rate kinetic and long dissociation from platelet half-life, despite the short plasma
Correspondence: Pierluigi Tricoci Duke Clinical Research Institute, 2400 Pratt Street, Room 03। I, Terrace Level, Durham, NC 27705, USA

Email trico00I@mc.duke.edu 


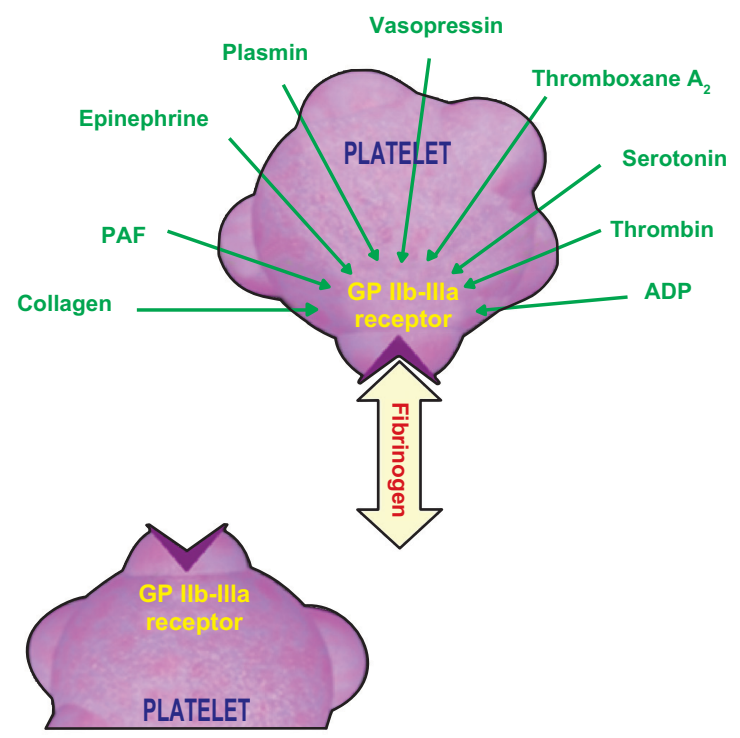

Figure I Mechanisms involved in platelet aggregation.

Abbreviations: ADP, adenosine diphosphate; PAF, platelet-activating factor.

half-life of the drug. Thus, the platelet inhibition with abciximab lasts approximately 48 hours after the drug is discontinued.

\section{Clinical trials of abciximab during elective $\mathbf{P C l}$}

Abciximab vs placebo

Abciximab was the first GP IIb/IIIa inhibitor studied in the setting of PCI, on top of aspirin and heparin. In the Evaluation of 7E3 for the Prevention of Ischemic Complications (EPIC) trial of 2099 patients undergoing PCI who were felt at high risk of ischemic complication, patients who received abciximab $(0.25 \mathrm{mg} / \mathrm{kg}$ bolus followed by $10 \mu \mathrm{g} / \mathrm{min}$ infusion for 12 hours) had a significant $35 \%$ reduction compared with placebo $(12.8 \%$ vs $8.3 \%, P=0.008)$ in the rate of the 30 days primary endpoint (a composite of death, nonfatal myocardial infarction, unplanned surgical revascularization, unplanned repeat percutaneous procedure, unplanned implantation of a coronary stent, or insertion of an intra-aortic balloon pump for refractory ischemia). ${ }^{4}$ No significant benefit was observed among patients receiving bolus alone. Patients receiving bolus and infusion of abciximab had an important increase in both the rate of major bleeding and transfusion, particularly CABG and vascular access site related bleeding.

The Evaluation in PTCA to Improve Long-Term Outcome with Abciximab GP IIb/IIIa Blockade (EPILOG) study evaluated a lower-risk population (patients with acute myocardial infarction or unstable angina were excluded) and compared 3 arms, abciximab plus standard dose of heparin

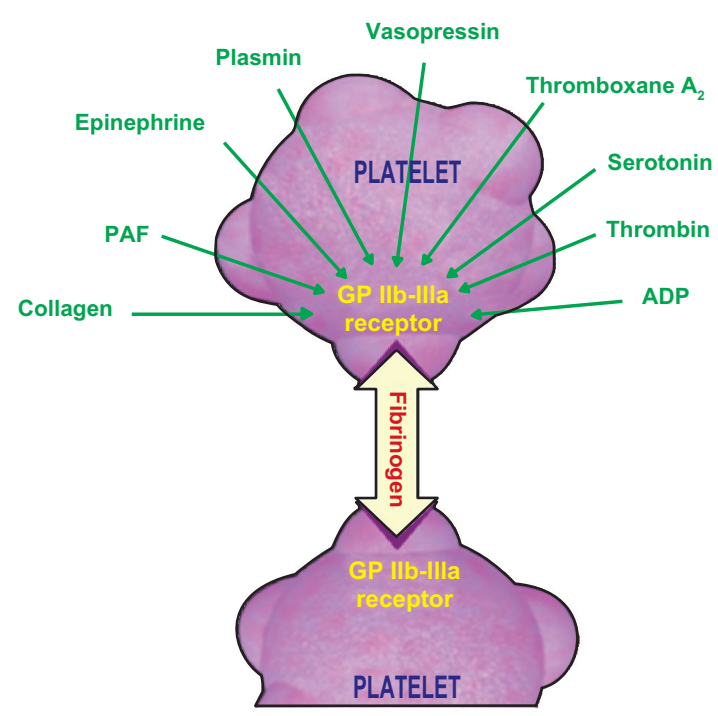

(100 U/kg bolus), abciximab plus moderate regimen of heparin (70 U/kg bolus), and placebo plus standard dose of heparin. ${ }^{5}$ The low-dose of heparin arm was introduced to reduce the rate of bleeding observed in the EPIC trial. The trial enrolled 2792 patients (of the 4800 planned) and was stopped after an interim analysis showed a $>50 \%$ reduction in the risk of the primary efficacy endpoint (death from any cause, myocardial infarction, or urgent revascularization within 30 days) in the 2 groups treated with abciximab. The rate of primary endpoint was $11.7 \%$ in the placebo group compared with $5.2 \%$ in the abciximab with low-dose heparin group (hazard ratio [HR] 0.43, 95\% confidence interval [CI] 0.30 to 0.60 ) and $5.4 \%$ in the abciximab with standarddose heparin group (HR $0.45,95 \%$ CI 0.32 to 0.63 ). Major bleeding was lower in the abciximab plus low dose heparin group $(2.0 \%)$ compared with patients in the abciximab plus standard-dose heparin group (3.5\%) and placebo plus standard-dose heparin group (3.1\%), although the differences were not statistically significant.

The benefit of abciximab in patients undergoing stent placement was evaluated in 2399 patients enrolled in the Evaluation of Platelet Inhibition in STENTing (EPISTENT) trial. ${ }^{6}$ Patients were randomized to receive stent plus abciximab, stent plus placebo, and balloon angioplasty plus abciximab. The primary endpoint was a composite of death, myocardial infarction, or need for urgent revascularization within 30 days. In patients receiving a stent there was a $52 \%$ reduction in the risk of the primary endpoint in the abciximab group compared with placebo (5.3\% vs $10.8 \%$; HR 0.48 , 
95\% CI 0.33 to 0.69 ). Patients in the balloon angioplasty plus abciximab group also had a lower rate of the primary endpoint than the stent plus placebo group (6.9\% vs $10.8 \%$; HR $0.6395 \%$ CI 0.45 to 0.88 ). Major bleeding occurred in $2.2 \%$ of patients in the stent plus placebo group, $1.5 \%$ in the stent plus abciximab group, and $1.4 \%$ in the balloon angioplasty plus abciximab; these differences were not statistically significant.

\section{Abciximab vs other GP Ilb/Illa inhibitors}

There is only one large phase 3 trial comparing in a "headto-head" fashion two different GP IIb/IIIa inhibitors. The Do Tirofiban and ReoPro Give Similar Efficacy Trial (TARGET) compared abciximab and tirofiban to demonstrate noninferiority of tirofiban. ${ }^{7}$ A total of 5308 patients undergoing PCI were assigned to receive either abciximab $(0.25 \mathrm{mg} / \mathrm{kg}$ bolus, followed by a 12 hours infusion of $0.125 \mu \mathrm{g} / \mathrm{kg} / \mathrm{min}$ ) or tirofiban $(10 \mu \mathrm{g} / \mathrm{kg}$ bolus, followed by 18 to 24 hours infusion of $0.15 \mu \mathrm{g} / \mathrm{kg} / \mathrm{min})$. All patients received heparin and aspirin and, when possible, a loading dose of clopidogrel. The primary endpoint occurred at a higher rate in the tirofiban group compared to the abciximab group (7.6\% vs $6.0 \%$, HR, 1.26; one-sided 95\% CI 1.51), which indicates that the 2 drugs were not equivalent, and actually abciximab proved superior to tirofiban. The rate of major bleeding or transfusion was similar in the 2 groups $(0.9 \%$ vs $0.7 \%)$. Some has argued that the tirofiban was not optimally dosed in the trial, because, as shown in the Comparison Of Measurements of
Platelet aggregation with Aggrastat, Reopro, and Eptifibatide (COMPARE) trial, the dosing regimen of tirofiban used produced less platelet aggregation inhibition at 15 to 30 minutes compared with abciximab or eptifibatide. ${ }^{8}$

\section{Abciximab in addition to clopidogrel}

The question of whether GP IIb/IIIa inhibitors are needed in the PCI setting with pretreatment with a high loading dose of clopidogrel is under debate, and not fully clarified. The question was addressed in the Intracoronary Stenting and Antithrombotic Regimen: Rapid Early Action for Coronary Treatment (ISAR-REACT) trial which included 2159 patients undergoing low-risk PCI. ${ }^{9}$ All patients were pretreated with $600 \mathrm{mg}$ of clopidogrel loading dose at least 2 hours before the intervention. Patients were then randomized to receive abciximab or placebo. The rate of the primary endpoint was similar in the two groups (4\% vs $4 \%$; relative risk [RR] 1.05 ; 95\% CI 0.69 to 1.59$)$, as was the rate of major bleeding (1\% vs 1\%). The ISAR-Is Abciximab a Superior Way to Eliminate Elevated Thrombotic Risk in Diabetics (SWEET) trial addressed a similar question in a population of 701 diabetes patients who underwent elective PCI after receiving a $600 \mathrm{mg}$ loading of clopidogrel. ${ }^{10}$ The incidence of death and myocardial infarction at 1 year was similar in the abciximab and placebo group (8.3\% vs $8.6 \%$; RR 0.97 , $95 \%$ CI 0.58 to 1.62 ).

None of the two previous studies evaluated high-risk ACS patients undergoing PCI. For this reason the ISAR-REACT2

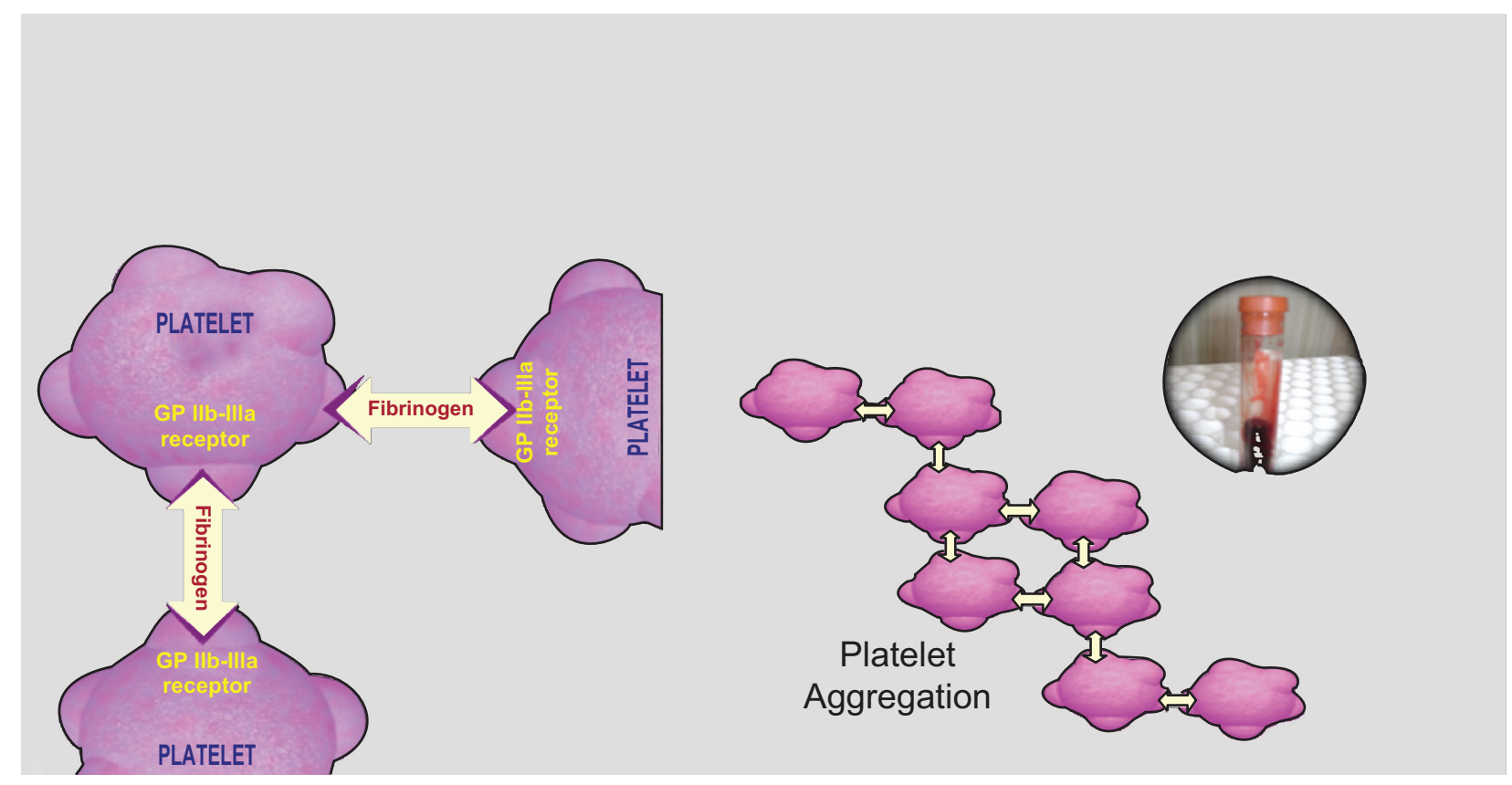

Figure 2 Platelet aggregation process. 
was necessary. This protocol included 2022 patients with cardiovascular high risk who received pretreatment with clopidogrel $600 \mathrm{mg}$ in the 2 hours before PCI and also aspirin $500 \mathrm{mg}$ po or iv. When they entered the catheterization lab, the patients was randomly assigned to 1) abciximab $0.25 \mathrm{mg} / \mathrm{kg}$ bolus, followed by a 12-hour infusion of $0.125 \mu \mathrm{g} /$ $\mathrm{kg} / \mathrm{min}$ [max dose $10 \mu \mathrm{g} / \mathrm{min}$ ] plus heparin $70 \mathrm{U} / \mathrm{kg}$, or 2) placebo bolus and 12-hour infusion, plus heparin bolus, 140 $\mathrm{U} / \mathrm{kg}$. The primary composite endpoint (death, myocardial infarction, or urgent target vessel revascularization (TVR) at 30 days) was reduced in patients in abciximab group. ${ }^{11}$

\section{Abciximab vs bivalirudin}

The Randomized Evaluation in PCI Linking Bivalirudin to Reduced Clinical Events (REPLACE)-2 trial evaluated 6010 patients undergoing elective or urgent PCI. ${ }^{12}$ Patients were randomized to receive heparin plus a GP IIb/IIIa inhibitor (abciximab or eptifibatide) or bivalirudin alone (with provisional use of GP IIb/IIIa inhibitors in case of complication during PCI). The trial aimed to establish the noninferiority of bivalirudin compared with heparin plus GP IIb/IIIa inhibitors on the composite of 30-day death, myocardial infarction, urgent repeat revascularization, or in-hospital major bleeding (net clinical outcome). Forty-three percent of patients in the GP IIb/III inhibitor group received abciximab. The rate of the net clinical outcome was comparable in the 2 groups $(10.0 \%$ vs $9.2 \%$ for heparin and bivalirudin groups, respectively; odds ratio [OR] $0.92,95 \%$ CI 0.77 to 1.09 ). There was a modest nonsignificant excess of ischemic complication at 30 days in the bivalirudin group compared to the heparin group $(7.6 \%$ vs $7.1 \%)$, whereas major bleeding $(2.4 \%$ vs $4.1 \% ; P<0.001)$ and transfusion $(2.5 \%$ vs $1.7 \% ; P=0.02)$ were significantly higher in the heparin group.

\section{Clinical trials of abciximab in patients with non-ST-segment elevation (NSTE) ACS undergoing PCI}

\section{Abciximab vs placebo}

The Chimeric 7E3 Antiplatelet Therapy in Unstable angina Refractory to standard treatment (CAPTURE) trial addressed the efficacy and safety of abciximab in patients with refractory unstable angina, defined as recurrent ischemia despite therapy with heparin and nitrates, and the benefit of abciximab administered as pretreatment before the procedure. ${ }^{13} \mathrm{~A}$ total of 1265 patients were randomized after angiography to receive either abciximab or placebo for 18 to 24 hour before PCI, and 1 hour following the procedure. The primary endpoint was death, myocardial infarction, or urgent intervention for recurrent ischemia within 30 days. The rate of the primary endpoint was $11.3 \%$ in the abciximab group and $15.9 \%$ in the placebo group $(P=0.012)$. Major bleeding was increased in the abciximab group (3.8\% vs $1.9 \% ; P=0.043)$.

A trial of abciximab in patients with NSTE ACS was also performed in patients not scheduled to undergo an early revascularization, the GUSTO IV-ACS. In this trial abciximab infusion ( 24 hours or 48 hours) did not show any benefit in reduction of death or myocardial infarction. ${ }^{14}$ Thus, in patients with NSTE ACS the use of abciximab is reserved only for those undergoing PCI, with the administration starting downstream in the cardiac catheterization. ${ }^{15}$

\section{Alternative abciximab modes of use}

The use of GP IIb/IIIa inhibitor in patients undergoing PCI through a radial vascular access is a potentially appealing strategy, because a radial approach is associated with less periprocedural bleeding complications than the traditional femoral approach, and therefore the use of this class of agent may have its benefit vs risk ratio maximized in this setting. The Early Discharge After Transradial Stenting of Coronary Arteries (EASY) study compared a single bolus of abciximab with discharge the same day with standard bolus and overnight infusion in 1005 patients undergoing transradial PCI. ${ }^{16}$ The authors concluded that a single bolus is noninferior to the traditional administration regimen in preventing the composite of death, myocardial infarction, repeat hospitalization, major bleeding, access site complication, and severe thrombocytopenia.

Another strategy of abciximab administration that has been studied is the intracoronary use. In a trial of 154 patients undergoing primary PCI, patients were randomized to receive either intracoronary bolus or intravenous bolus, both followed by standard intravenous infusion. ${ }^{17}$ The primary endpoint was the infarct size and extent of microvascular obstruction evaluated with delayed-enhancement MRI. The rationale of intracoronary bolus is to achieve a higher intracoronary concentration and by this mean coronary flow may be improved. In this study the intracoronary administration significantly reduced both the infarct size and microvascular obstruction. These results clearly need to be confirmed on a larger scale to address whether intracoronary revascularization improves clinical outcome.

\section{Abciximab in addition to clopidogrel}

The ISAR-REACT 2 evaluated whether abciximab was superior to placebo in NSTE ACS patients pretreated with 

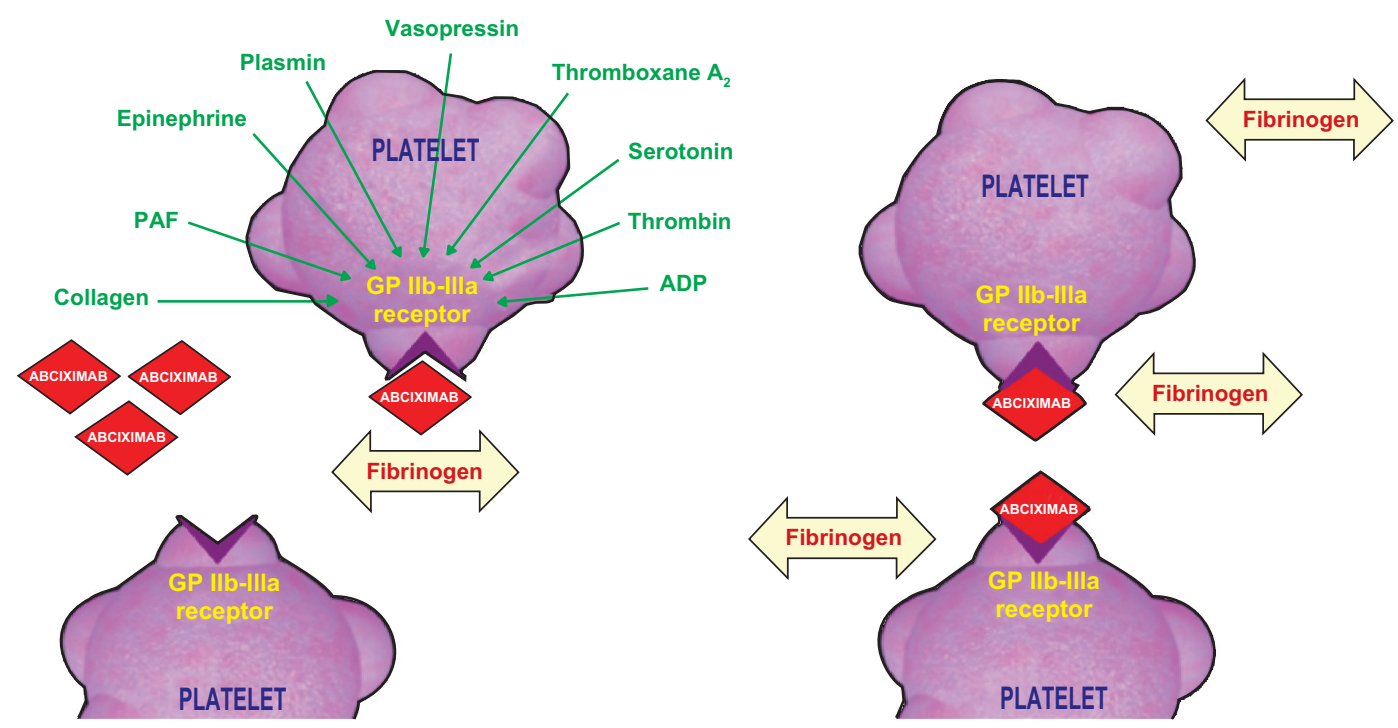

Figure 3 Abciximab interaction with platelet.

Abbreviations: ADP, adenosine diphosphate; PAF, platelet-activating factor.

clopidogrel $600 \mathrm{mg}$ loading dose prior to PCI. Among the 2022 patients included in the trial, the abciximab group had $25 \%$ reduction in the risk of death, myocardial infarction, or urgent target vessel revascularization (8.9\% vs $11.9 \%$; RR $0.75,95 \%$ CI 0.58 to 0.97$).{ }^{9}$ A subgroup analysis showed that only troponin-positive patients had a benefit from abciximab, a finding similar to that of other studies. The rate of major bleeding (1.4\% vs $1.4 \%$; RR $1.00,95 \%$ CI 0.50 to 2.08 ) was similar in the 2 groups.

\section{Abciximab vs bivalirudin}

The randomized Acute Catheterization and Urgent Intervention Strategy (ACUITY) trial evaluated 3 different strategies among 13,819 patients with NSTE ACS: heparin plus a GP IIb/IIIa inhibitor, bivalirudin plus a GP IIb/IIIa inhibitor, or bivalirudin alone. ${ }^{18}$ The primary objective of the trial was to establish noninferiority of the bivalirudin regimens, compared to heparin plus GP IIb/IIIa inhibitors on the primary net benefit endpoint of 30-day death, MI, unplanned revascularization for ischemia (composite ischemic endpoint) or major bleeding. A total of 7789 patients underwent PCI in the trial. The trial was open label and the decision of which GP IIb/IIIa inhibitor to use was left to the treating physician; in the group of patients who were randomized to receive a GP IIb/IIIa inhibitor abciximab was the drug of choice at the time of PCI in $17 \%$ of patients (the majority of patients received eptifibatide). Patients receiving bivalirudin plus GP IIb/IIIa inhibitor group and heparin plus GP IIb/IIIa inhibitor group had similar efficacy and safety outcomes. In the bivalirudin-alone group the rate of the net clinical outcome was significantly lower than in the heparin plus GP IIb/IIIa inhibitor group (10.1\% vs 11.7\%; RR 0.86, 95\% CI 0.77 to 0.97 ), which was entirely driven by a lower rate of bleeding (3.0\% vs $5.7 \%$; RR 0.53 , 95\% CI 0.43 to $0.65)$. There was a nonsignificant numerical increase in the ischemic complications in the bivalirudin-alone group (7.8\% vs 7.3\%; RR 1.08, 95\% CI 0.93 to 1.24 ) which did not exceed the prespecified $25 \%$ margin for noninferiority.

\section{Trials of abciximab in patients with ST-segment elevation mycocardial infarction (STEMI) undergoing primary $\mathbf{P C I}$}

The Controlled Abciximab and Device Investigation to Lower Late Angioplasty Complication (CADILLAC) trial included 2082 STEMI patients who received, in a factorial design, balloon angioplasty vs stenting, and abciximab or balloon angioplasty/stenting alone. ${ }^{19}$ The incidence of 6-month death, reinfarction, disabling stroke, and ischemia-driven TVR was increased in the balloon angioplasty alone (20.0\%) compared with balloon angioplasty plus abciximab (16.5\%), stenting alone (11.5\%), and stenting plus abciximab (10.2\%) groups, suggesting that abciximab did not provide a significant additional advantage in patients receiving a coronary stent.

In a meta-analysis of studies comparing abciximab with placebo in STEMI patients undergoing primary stenting, including 1101 patients a significant reduction in the risk of 
death or reinfarction ( $19.0 \%$ vs $12.9 \%$; RR $0.63,95 \%$ CI 0.45 to 0.89 ) and a reduction in mortality (14.3\% vs $10.9 \%$; RR $0.70,95 \%$ CI 0.48 to 1.00 ) was observed in patients treated with abciximab. ${ }^{20}$ The rates of major bleeding were $2.5 \%$ in the abciximab group and $2.0 \%$ in the placebo group.

The Facilitated Intervention with Enhanced Reperfusion Speed to Stop Events (FINESSE) study compared, in 2452 STEMI patients undergoing primary PCI, 2 facilitated strategies (abciximab alone or combination of abciximab and reduceddose reteplase) with the use of abciximab in the catheterization lab. ${ }^{21}$ The primary endpoint was the composite of death, ventricular fibrillation occurring $>48$ hours after randomization, cardiogenic shock, and congestive heart failure during the first 90 days after randomization. The primary endpoint was not statistically different in the 3 groups $(9.8 \%$ of the patients in the combination-facilitated PCI group; $10.5 \%$ abciximabfacilitated PCI group; and $10.7 \%$ in the primary-PCI group with downstream abciximab; $P=0.55$ ). Thus, upstream treatments with abciximab in the setting of primary PCI did not differ with the use of the drug at the time of PCI.

The Harmonizing Outcomes with Revascularization and Stents in Acute Myocardial Infarction (HORIZONS-AMI) study was an open-label clinical trial comparing bivalirudin alone with heparin plus a GP IIb/IIIa inhibitor in patients with STEMI undergoing primary PCI. ${ }^{22}$ A total of 3602 patients was enrolled and abciximab was the agent selected in $52 \%$ of patients in the heparin plus GP IIb/IIIa inhibitor group. The two co-primary end points were major bleeding and a net clinical outcome including major bleeding or a major ischemic event within 30 days. Patients who received bivalirudin alone had a reduction in the net clinical outcome $(9.2 \% \mathrm{vs}$ $12.1 \%$; RR 0.76 ; $95 \%$ CI 0.63 to 0.92 ), entirely driven by a lower rate of major bleeding $(4.9 \%$ vs $8.3 \%$; RR 0.60 , $95 \% \mathrm{CI}, 0.46$ to 0.77 ). On the other hand patients in the bivalirudin group had an increased rate of stent thrombosis in the first 24 hours. Of note, bivalirudin alone resulted in a significant reduction of mortality at 30 days $(2.1 \%$ vs $3.1 \%$; RR $0.66,95 \%$ CI 0.44 to 1.00 ), which the authors attributed to the reduction in bleeding.

The Multicentre Evaluation of Single High-Dose Bolus Tirofiban vs Abciximab With Sirolimus-Eluting Stent or Bare Metal Stent in Acute Myocardial Infarction (MULTISTRATEGY) Trial, as a part of a factorial design, tried to assess whether high-dose bolus of tirofiban was noninferior to abciximab in inducing ST-segment resolution at 90 minutes in 745 patients with STEMI treated with primary PCI. ${ }^{23}$ Patients were also randomized to receive a sirolimuseluting stent vs bare metal stent. ST-segment resolution occurred in $83.6 \%$ in the abciximab group and $85.3 \%$ in the tirofiban group, meeting the specified noninferiority criteria (RR 1.020; $97.5 \%$ CI 0.958 to 1.086). Ischemic and bleeding complication was similar in the 2 groups.

A high-dose bolus regimen of tirofiban in STEMI patients treated with primary PCI was also tested against abciximab in the Facilitated Angioplasty with Tirofiban or Abciximab (FATA) study, including 692 patients. Unlike the MULTISTRATEGY, the study failed to show a noninferiority, as specified in this trial, of tirofiban versus abciximab in the rate of ST-segment resolution at 90 minutes ( $67 \%$ vs $70 \%$ in the abciximab and tirofiban groups, respectively). ${ }^{24}$ Nonetheless the absolute difference between the 2 groups was comparable across the 2 trials.

\section{Current PCI guidelines recommendation}

Abciximab is one of the agents of choice recommended by current ACC/AHA guidelines in patients undergoing PCI. ${ }^{25}$ The ACC/AHA/SCAI 2005 PCI practice guidelines recommend (class 1, level of evidence A) the use of a GP IIb/IIIa inhibitors (abciximab, eptifibatide, or tirofiban) in patients with unstable angina (UA)/NSTEMI undergoing PCI but who are not pretreated with clopidogrel. ${ }^{26}$ In UA/NSTEMI patients who received clopidogrel the recommendation is less certain (class II, level of evidence B). The guidelines also recommend, as class II recommendation (level of evidence B), the use of early abciximab in patients with STEMI undergoing PCI, and the use of a GP IIb/IIIa inhibitor in patients undergoing elective PCI and stent.

\section{Conclusion}

Abciximab, as one of the most largely studied antiplatelet agents, currently represents a valuable therapeutic choice in the treatment of patients undergoing PCI for a broad spectrum of clinical indications.

\section{Disclosures}

Dr Tricoci has received research grants from the Schering-Plough Research Institute through the Duke Clinical Research Institute and has served on the ScheringPlough Advisory Board.

\section{References}

1. Centers for Disease Control and Prevention: Morbidity and Mortality Weekly Report, JAMA. 2007;297:1308-1309.

2. Kung Hsiang-Ching, Hoyert Donna L, Xu Jiaquan, Murphy Sherry L. Deaths: Final Data for 2005, National Vital Statistics Reports, Volume 56, Number 10, April 24, 2008. 
3. American Heart Association Website, Heart Disease and Stroke Statistics - 2008 Update: p. 37. URL: http://www.americanheart.org/ downloadable/heart/1200082005246HS_Stats\%202008.final.pdf.

4. EPIC Investigation. Use of a monoclonal antibody directed against the platelet glycoprotein IIb/IIIa receptor in high-risk coronary angioplasty. N Engl J Med. 1994;330:956-961.

5. EPILOG Investigators. Platelet glycoprotein IIb/IIIa receptor blockade and low-dose heparin during percutaneous coronary revascularization. N Engl J Med. 1997;336:1689-1696.

6. EPISTENT Investigators. Randomised placebo-controlled and balloonangioplasty controlled trial to assess safety of coronary stenting with use of platelet glycoprotein- IIb/IIIa blockade. The EPISTENT investigators. Evaluation of platelet IIb/IIIa inhibitor for stenting. Lancet. 1998;352:87-92.

7. Topol EJ, Moliterno DJ, Herrmann HC, et al. Comparison of two platelet glycoprotein IIb/IIIa inhibitors, tirofiban and abciximab, for the prevention of ischemic events with percutaneous coronary revascularization. N Engl J Med. 2001;344:1888-1894.

8. Batchelor WB, Tolleson TR, Huang Y, et al. Randomized comparison of platelet inhibition with abciximab, tirofiban and eptifibatide during percutaneous coronary intervention in acute coronary syndromes: the COMPARE trial; comparison of measurements of platelet aggregation with aggrastat, reopro, and eptifibatide. Circulation. 2002;106:1470-1476.

9. Kastrati A, Mehilli J, Neumann FJ, et al. Abciximab in patients with acute coronary syndromes undergoing percutaneous coronary intervention after clopidogrel pretreatment: the ISAR-REACT 2 randomized trial. JAMA. 2006;295:1531-1538.

10. Mehilli J, Kastrati A, Schuhlen H, et al. Randomized clinical trial of abciximab in diabetic patients undergoing elective percutaneous coronary interventions after treatment with a high loading dose of clopidogrel. Circulation. 2004;110:3627-3635.

11. Kastrati A, Mehilli J, Neumann FJ, et al. Abciximab in patients with acute coronary syndromes undergoing percutaneous coronary intervention after clopidogrel pretreatment. The ISAR-REACT 2 Randomized Trial. JAMA. 2006;295:1531-1538.

12. Lincoff AM, Bittl JA, Harrington RA, et al. Bivalirudin and provisional glycoprotein IIb/IIIa blockade compared with heparin and planned glycoprotein IIb/IIIa blockade during percutaneous coronary intervention: REPLACE-2 randomized trial. JAMA. 2003;289:853-863.

13. Randomised placebo-controlled trial of abciximab before and during coronary intervention in refractory unstable angina: the CAPTURE Study. Lancet. 1997;349:1429-1435.

14. GUSTO IV-ACS Investigators. Effect of glycoprotein IIb/IIIa receptor blocker abciximab on outcome in patients with acute coronary syndromes without early coronary revascularisation: the GUSTO IV-ACS randomised trial. Lancet. 2001;357:1915-1924.

15. James S, Armstrong P, Califf R, et al. Safety and efficacy of abciximab combined with dalteparin in treatment of acute coronary syndromes. Eur Heart J. 2002;23:1538-1545.
16. Bertrand OF, De Larochelliere R, Rodes-Cabau J, et al. A randomized study comparing same-day home discharge and abciximab bolus only to overnight hospitalization and abciximab bolus and infusion after transradial coronary stent implantation. Circulation. 2006;114:2636-2643.

17. Thiele H, Schindler K, Friedenberger J, et al. Intracoronary compared with intravenous bolus abciximab application in patients with ST-elevation myocardial infarction undergoing primary percutaneous coronary intervention: the randomized Leipzig immediate percutaneous coronary intervention abciximab IV versus IC in ST-elevation myocardial infarction trial. Circulation. 2008;118:49-57.

18. Stone GW, McLaurin BT, Cox DA, et al. Bivalirudin for patients with acute coronary syndromes. $N$ Engl J Med. 2006;355:2203-2216.

19. Stone GW, Grines CL, Cox DA, et al. A prospective, randomized trial comparing primary balloon angioplasty with or without abciximab to primary stenting with or without abciximab in acute myocardial infarction - primary endpoint analysis from the CADILLAC Trial. N Engl J Med. 2002;346:957-966.

20. Montalescot G, Antoniucci D, Kastrati A, et al. Abciximab in primary coronary stenting of ST-elevation myocardial infarction: a European meta-analysis on individual patients' data with long-term follow-up. Eur Heart J. 2007;28:443-449.

21. Ellis SG, Armstrong P, Betriu A, et al. Facilitated percutaneous coronary intervention versus primary percutaneous coronary intervention: design and rationale of the facilitated intervention with enhanced reperfusion speed to stop events (FINESSE) trial. Am Heart J. 2004;147:E16.

22. Stone GW, Witzenbichler B, Guagliumi G, et al. Bivalirudin during primary PCI in acute myocardial infarction. $N$ Engl $\mathrm{J} \mathrm{Med}$. 2008;358:2218-2223.

23. Valgimigli M, Campo G, Percoco G, et al; on behalf of the Multicentre Evaluation of Single High-Dose Bolus Tirofiban vs Abciximab With Sirolimus-Eluting Stent or Bare Metal Stent in Acute Myocardial Infarction Study (MULTISTRATEGY) Investigators. JAMA. 2008; 299:1788-1799.

24. Marzocchi A, Manari A, Piovaccari G, et al; FATA Investigators. Randomized comparison between tirofiban and abciximab to promote complete ST-resolution in primary angioplasty: results of the facilitated angioplasty with tirofiban or abciximab (FATA) in ST-elevation myocardial infarction trial. Eur Heart J. 2008;29:2972-2980.

25. King SB III, Smith SC, Hirshfeld JW, Jacobs AK, Morrison DA, Williams DO. Focused update of the ACC/AHA/SCAI. 2005 Guideline update for percutaneous coronary intervention. J Am Coll Cardiol. 2008;51:172-209.

26. Smith SC Jr, Feldman TE, Hirshfeld JW Jr, et al. ACC/AHA/SCAI 2005 guideline update for percutaneous coronary intervention: a report of the American College of Cardiology/American Heart Association Task Force on Practice Guidelines (ACC/AHA/SCAI Writing Committee to Update the 2001 Guidelines for Percutaneous Coronary Intervention) J Am Coll Cardiol. 2006;47:e1-e121.
Vascular Health and Risk Management

\section{Publish your work in this journal}

Vascular Health and Risk Management is an international, peerreviewed journal of therapeutics and risk management, focusing on concise rapid reporting of clinical studies on the processes involved in the maintenance of vascular health; the monitoring, prevention and treatment of vascular disease and its sequelae; and the involvement of

\section{Dovepress}

metabolic disorders, particularly diabetes. This journal is indexed on PubMed Central and MedLine. The manuscript management system is completely online and includes a very quick and fair peer-review system, which is all easy to use. Visit http://www.dovepress.com/ testimonials.php to read real quotes from published authors. 